\title{
Eco-friendly Retail Product Attributes, Customer Attributes and the Repurchase Intentions of South African Consumers
}

Job Dubihlela, Cape Peninsula University of Technology, South Africa

Tandiswa Ngxukumeshe, Nelson Mandela Metropolitan University, South Africa

\begin{abstract}
Purpose-Consumers are becoming progressively aware of the significance of eco-friendly activities, and their environmental consciousness drives them to consume eco-friendly products and services more, and prefer to support organisations that favor conservational practices. Increased environmental impacts bring a rise in concerns locally and globally, on sustainability issues aimed at reducing non-conservative consumption patterns. Retail organisations are increasingly developing and marketing eco-friendly retail products to promote sustainable, ecofriendly consumption patterns. The purpose of this paper is to examine the relationships between eco-friendly retail product attributes and South African consumers' eco-friendly product repurchase intentions.
\end{abstract}

Design/methodology/approach - A survey approach was employed involving 241 consumers in Southern Gauteng. Confirmatory factor analysis and structural equation analysis were conducted respectively to test the reliability and validity of the scales as well as the proposed hypotheses.

Research findings-Retail product consumers' response to the attributes of eco-friendly products is still important in predicting their eco-friendly product repurchase intentions. South African consumers' eco-friendly attributes moderate their environmental sensitivity, hence their repurchase intentions.

Practical implications - It is not enough to retailers and wholesalers to promote sustainable and recyclable packaging materials. They must also improve eco-friendly product-related attributes to satisfy consumer needs better, and should be cautious in the direct and moderating effect of eco-friendly customer-related attributes in devising marketing plans to promote eco-friendly products.

Originality/value - The paper contributes to research by advancing understanding of how consumers make their repurchase intentions of eco-friendly retail products, providing retailers with managerial insights. The paper also presents limitations and directions for future research.

Keywords: South Africa, Eco-friendly products, Repurchase intentions, Retail product-related attributes, Customer attributes

\section{INTRODUCTION}

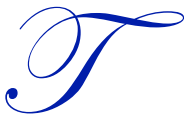

he unabated fierce and stiff competition and the environmental sustainability issues continuously push retailers to focus on the environmental impact of their products (Boztepe, 2012; Fisher, Bashyal \& Bachman, 2012; Radwan, Jones \& Minoli 2010). This competition and the environmental sustainability issues are intensified by the changing shopping patterns of consumers, as they are increasingly becoming environmentally conscious (Cheah \& Phau, 2011). Consumers' preference for using eco-friendly products and services, and their choice of which retailer to deal with, has continuously changed the way retailers do business. In response to this increasing interest, retailers are becoming more environmentally responsible and have adopted green marketing through the development of products that meet the demands of environmentally conscious consumers (Tan \& Yeap, 2012). This green effort has enabled organisations to gain competitive advantages and 
assist in enhancing customer satisfaction, market demand (Manaktola \& Jauhari, 2007), ecological performance and corporate image (Wan, 2007).

While it is acknowledged that there is a lot of effort put by organisations that are focusing on sustainability and environmentally friendly products and services, understanding how consumers make their repurchase intentions of eco-friendly retail products still need attention. Thus, it is suggested that investigating consumer attributes about product attributes would be more practical for the development of business strategies (D'Souza, Taghian, \& Khosla, 2007:70). Traditional product attributes such as price, quality, and brand are still the most important attributes that consumers consider when making the green purchasing decision.

\section{Eco-Friendly Products}

Seminal research by Fishbein (1967) long defined a product as a bundle of attributes and consumers' preference for these attributes may be diverse (Lai \& Wong, 2012). In the context of eco-friendly products, such product attributes should include a significant achievement in reducing the environmental impact; recyclable, bio-degradable, ozonefriendly, renewable, re-usable, and so on (Morris, Hastak, \& Mazis, 1995). Environmental attributes of products have been incorporated in many public policies and regulations, and initiatives have been put in place to ensure that the environment is protected (Park \& Oh, 2005). For example, many organisations have devised ways of encouraging communities to recycle glass, papers, plastics, etc. through the use of recycling bins; reduced energy consumption through finding alternative ways of using energy, and so on. However, traditional product attributes such as price, quality, and brand are still the most important attributes that consumers consider when making green purchasing decision. Very often, consumers identify eco-friendly products through information provided, for example, on product labels and media advertisements. However, detecting the quality of environmentally safe products remains questionable due to issues such as information credibility, consumer education and product certification (Wagner, 1997).

\section{Eco-Conscious Consumers}

An eco-conscious consumer is a consumer that is more mindful about environmental issues and follows an environmentally friendly lifestyle that results in diminished environmental problems in the purchase, use or disposal of goods (Ahn \& Park, 1998). Environmentally friendly consumers are sensitive towards the environmental effects when they purchase products and are personally active in their involvement in energy conservation and eco-friendly behaviour (Balderjahn, 1988). A study by (Park \& Oh, 2005) categorizes an eco-conscious behaviour as resource conservation, public awareness, environmental preservation and recycling consciousness. Such behaviour gives consumers a sense of activity and participation in environmental initiatives that ensure the preservation of the environment for more generations to come. Moreover, Park and Oh (2005) maintain that environmentally conscious consumers have a detailed and professional knowledge of the environment and are highly responsible. Also, Kollmus and Agyeman (2002) aver that these consumers seek to minimize the negative impact of one's actions on the natural resources and minimize resource and energy consumption, use non-toxic substances/products, and reduce waste production. Studies show that environmentally conscious consumers are well educated and prefer a service or product that is environmentally sustainable (Bang, Ellinger, Hadjimarcou, \& Traichal, 2000).

\section{Consumer Attitudes Towards Eco-Friendly Products}

Due to environmental problems caused by excessive use of energy and non-renewable natural resources, environmentally unfriendly production processes and environmental disasters, an increasing number of consumers are now aware of ecological issues. Consumers are changing their behaviour towards shopping and often express environmental concerns (Kalafatis, Pollard, East, \& Tsogas, 1999). Sung (2005) define an environmentally friendly attitude as the one that results in the purchase or consumption of environmentally friendly products. Contrary, Laroche, Bergeron, Tomiul and Barbaro-Forleo (2002) argue that consumer attitude towards environmental issues does not necessarily lead to actual environmentally friendly purchasing behaviour.

Researchers, such as Laroche et al. (2002) submit that an eco-friendly attitude involves the four-dimensionality structure of attitudes which include (1) perceived severity of environmental problems, (2) inconvenience of being 
environmentally friendly, (3) importance of pro-environmental behaviour, and (4) perceived level of corporate responsibility. However, Wan (2007) argue that an environmental attitude is acquired over a long period of time. According to Bhaduri and Ha-Brookshire (2011), though many individuals may have a high ecological concern, they may feel that environmental preservation is government's and/or big corporations' responsibility. On the other hand, studies show that consumers who have higher knowledge of ecological problems are more willing to pay higher prices to support green product than those who have low knowledge (Vining \& Ebreo, 1990).

\section{Repurchase Intentions}

Repurchase intention refers to the consumer's willingness to repeat-buy over an extended period of time from the same retailer (Ismail \& Safa, 2014). Some authors refer to it as the individual's judgment about buying a designated product or service again from the same provider (Chinomona \& Dubihlela 2014). Borrowing from the definition of Seiders et al. (2005), repurchase intentions would represent the customer's self-reported likelihood of engaging in further repurchase behaviour. Marketing managers in contemporary business rely on repurchase intentions to predict sales and increase profits in a variety of marketing activities (Pérez et al., 2007); making the repurchase intentions construct a critical research component in retail marketing.

\section{THEORETICAL FRAMEWORK}

According to Sachdev et al. (2011), environmentally friendly activities and eco-friendly products comprises of every activity intended to facilitate and generate several exchanges aimed at satisfying consumer wants or needs, in a way that the satisfaction of those particular wants and needs take place, with a less harmful effect on the physical environment. Numerous studies have investigated eco-friendly products, as well as consumer behaviour towards these products. Consumers and firms around the world are becoming even more aware about the global warming concept leading people to gain interest regarding environmental development. Consumers are showing more interest concerning ecological issues. Previous studies have shown that consumers are interested and concerned about ecological problems is transforming their attitudes (Haider \& Tahir, 2012).

Since businesses are recognising that they are part of a broader community, they are becoming more socially responsible and are heading towards the introduction of products of an eco-friendly nature (Cheah \& Phau, 2011; Haider et al., 2012). Green marketing efforts are to move marketing theory and practice away from the economic hyperspace it has grown into, and bring it back to earth and reality (Boztepe, 2012). Today, business firms view green and sustainability development issues as market opportunities rather than simply regulations to be complied by (Cheah et al., 2011).

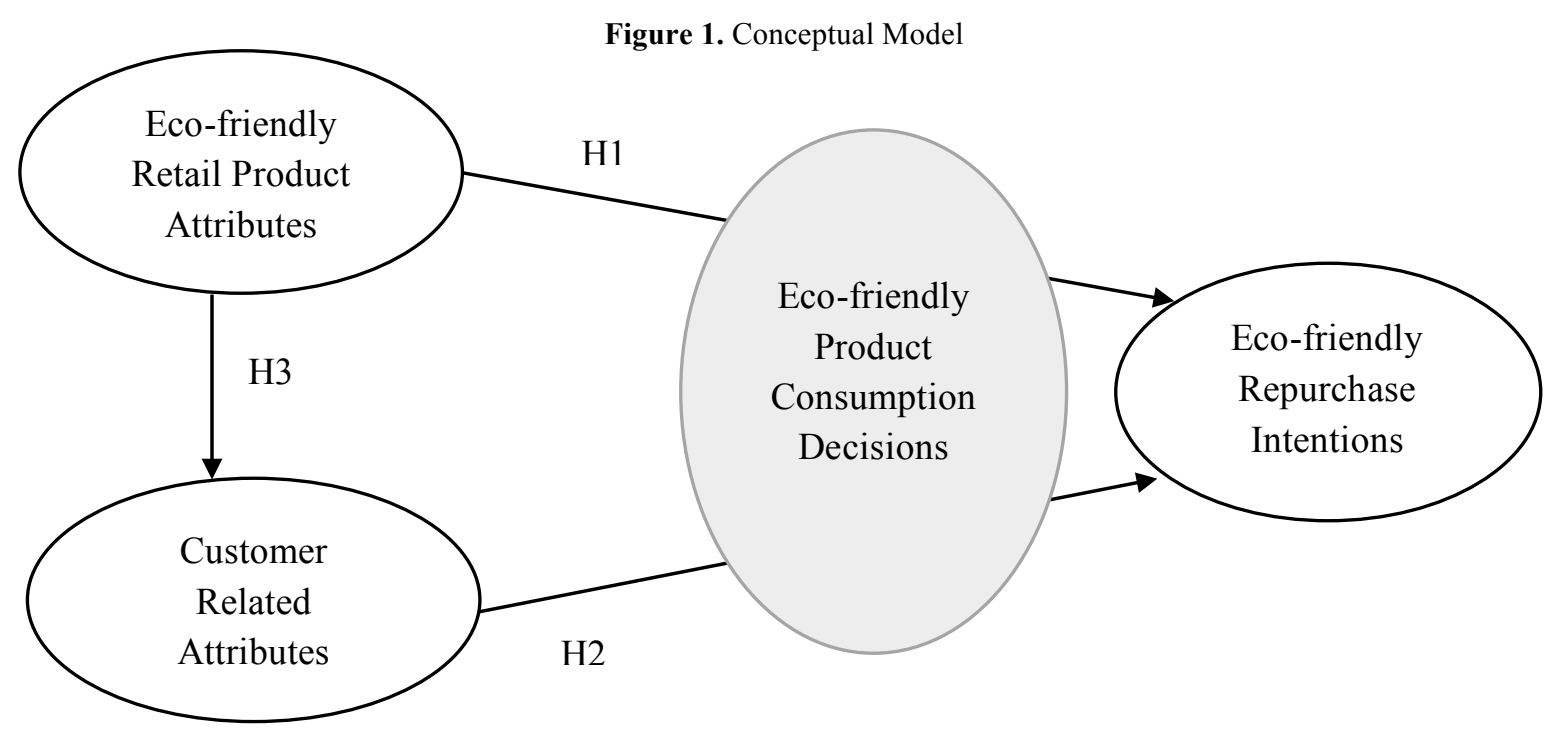




\section{Research Hypotheses}

H1: Eco-friendly product attributes (EfPA) have a positive relationship with consumers' eco-friendly repurchase intentions (EfRI)

H2: The customer related eco-friendly attributes, i.e. characteristics of eco-friendly consumers (CeFA) have a positive relationship with their eco-friendly repurchase intentions (EfRI)

H3: Eco-friendly product related attributes (EfPA) have a positive relationship with customers' related attributes (the characteristics of eco-friendly consumers) (EfCA)

\section{PROBLEM STATEMENT}

The perpetually deteriorating state of the environment has impelled advocacy towards environmental consciousness within and without business operations, igniting consumer awareness and eco-friendly attitudes towards products (Boztepe, 2012). However, achieving the resolution of environmental protection has turned out to be a global challenge. Companies are utilizing numerous methods to encourage consumers to remain environmentally conscious of changing their attitudes towards eco-friendly products as well as satisfying their needs (Fisher et al. 2012). There are several consumer behaviour studies regarding the environment. However, the majority of them focus on one or two elements of the marketing-mix.

Research concerning eco-friendly products have concentrated on quality dimensions and pricing. Some studies have considered eco-friendly products to be of great quality compared to conventional ones, then again, results from other studies indicates the opposite (Sachdev et al. 2011). Certain studies have investigated consumer preparedness to pay higher prices for ecological products while in other studies have focused on customer sensitivity to premium pricing (Fisher et al. 2012). However, they do not cover the factors utilized by companies to make consumers purchase green products as well as the consumers' attitudes towards these products (Boztepe, 2012); let alone the impact of eco-friendly product attributes and customer characteristics on eco-friendly product repurchase intentions. Also, much research on these behavioural components have been limited to developed markets. This study investigates eco-friendly retail product attributes, customer attributes and the repurchase intentions within a youth market of South Africa.

\section{RESEARCH METHODOLOGY}

\section{Study Design and Sampling}

This cross-sectional study used a random sample selected by inviting customers who shopped at different grocery retail stores in shopping malls in Southern Gauteng, to complete the interviewer-administered questionnaires. Although the choice of the Southern Gauteng region has no particular theoretical motivation, however the region suffers from high levels of industrial refuse disposal, diminishing water quality and polluted landfill space. In comparison with other parts of South Africa and other African regions, consumers in Southern Gauteng, particularly those in Vereeniging and Vanderbijlpak (the Vaal Triangle Industrial Hub) are at the stage of 'environmental protection awakening'. In fact, most consumers in the Sedibeng and Emfuleni municipal areas have for a long time been negatively affected by pollution, and have grown to understand the gravity of environmental pollution and the subsequent impact it has on their own health. For this reason researchers believe these consumers are ecologically unique in some way. They have gradually become more open to environmentally awareness issues. A total of 400 questionnaires were administered by both the researcher and 9 trained interviewers, and of the sample only 241 of questionnaires were correctly completed and usable (representing $60.3 \%$ response rate), mainly due to contaminated questionnaires and time and resource constraints.

\section{Measuring Instruments}

The three main constructs used in this study were adapted in line with literature. The eco-friendly retail product attributes (EfPA) construct as reflected by three indicators in section B of the questionnaire, namely product design, 
quality, and price, were adapted from Joergens (2006) and Bhaduri and Ha-Brookshire (2011). The customer related attributes (EfCA) construct in section C, sometimes called customer characteristics, was also adapted from Bhaduri and Ha-Brookshire (2011). The respondents were asked to assess the level of importance of these dimensions using a five-point Likert scale, with 1 representing extremely unimportant and 5 representing extremely important. The measurement of eco-friendly product repurchase intentions (EfRI) in section D, was adapted from Tan and Yeap (2012). Respondents were asked to indicate the degree to which they are likely to buy again products with "recycled content," and "products that is safe for the environment," using a five-point Likert scale. As this paper is still work in progress, a full report of the scale and respondent profile shall be reported in the ensuing main paper.

\section{DATA ANALYSIS}

Descriptive data, reliability and validity of the constructs as well as the proposed hypotheses were tested in SPSS 22.0. To execute the statistical methods, calculate the test statistic and logical deduction of study's hypotheses, the most important thing was to specify a suitable statistical method for the research, by testing data distribution as the basic priority. So the reliable Kolmogorov-Smirnov test was used for investigating the theory of normality of research data (Delafrouz et al. 2014). As the meaningfulness level for all variables was above 0.05, so all investigated variables in the present research have a normal distribution. Therefore, we used parameter methods. All constructs' AVE values were also calculated, to test the convergent validity and if 50 percent of variances. The square roots of AVE for the constructs under investigation will be compared with the correlations of the constructs, to check the discriminant validity in line with Joergens (2006). Table 1 provides the demographic details of the respondents.

Table 1. Demographic details of the respondents

\begin{tabular}{|c|c|c|}
\hline \multicolumn{3}{|c|}{ Gender of respondents } \\
\hline Male & 104 & 43.2 \\
\hline Female & 137 & 56.8 \\
\hline Total & 241 & 100.0 \\
\hline \multicolumn{3}{|l|}{ Age of respondents } \\
\hline 15 years and below & 0 & 0.0 \\
\hline $15-24$ years & 52 & 21.5 \\
\hline $25-34$ years & 101 & 42.1 \\
\hline $35-44$ years & 32 & 13.2 \\
\hline $45-54$ years & 27 & 11.4 \\
\hline 55 years and above & 4 & 1.8 \\
\hline Total & 241 & 100.0 \\
\hline \multicolumn{3}{|c|}{ Respondents' Educational Level } \\
\hline Primary and below & 30 & 12.5 \\
\hline High School Certificate & 58 & 24.2 \\
\hline Graduate (Degree/Diploma) & 124 & $51.4^{*}$ \\
\hline Postgraduate & 29 & $11.9^{*}$ \\
\hline Total & 241 & 100.0 \\
\hline \multicolumn{3}{|c|}{ Income level (Rand per month) } \\
\hline Below R1,000 & 4 & 1.6 \\
\hline $\mathrm{R} 1,000-3,999$ & 7 & 2.7 \\
\hline $\mathrm{R} 4,000-6,999$ & 41 & 17.1 \\
\hline R7,000-9,999 & 51 & 21.3 \\
\hline R10,000-12,999 & 61 & 25.2 \\
\hline R13,000-15,999 & 50 & 20.9 \\
\hline \multirow[t]{2}{*}{$\mathrm{R} 16,000$ or above } & 27 & 11.2 \\
\hline & 241 & 100 \\
\hline
\end{tabular}

Preliminary analysis shows that data was collected from respondents that resided close to universities in Gauteng, 56.7 percent of respondents were reported to be university students, with an average age of 19.8 -years old. Because the majority of the respondents were full-time students in university, with some working on a part-time basis, the 
average monthly income is R2,979.87 per month. The demographic details in Table 2 report $56,8 \%$ female, $43,2 \%$ male; $21,3 \%$ frequently buy eco-friendly products, $63,6 \%$ age band of $15 \mathrm{yrs}$ to $34 \mathrm{yrs}$. It is noteworthy to report that $59,2 \%$ of the respondents know the importance of eco-friendly; and that $57.3 \%$ earn more than R10,000. This could be indicating that the high the income the more the behaviour becomes e-eco-friendly.

\section{Structural Equation Modelling Approach}

In order to analyse the measurement and structural models statistically, this study used Smart PLS software for structural equation modelling (SEM) technique (Ringle et al., 2005). In SEM, the measurement model refers to the linkages between the latent variables and their manifest variables, and the structural model captures the hypothesised causal relationships among the research constructs (Delafrouz et al. 2014). SEM enables the simultaneous examination of both the path (structural) and factor (measurement) models in one model. In addition, Smart PLS combines a factor analysis with near regressions, makes only minimal assumptions, with the goal of variance explanation (high R-square) (Anderson \& Gerbing, 1988). Furthermore, Smart PLS supports both exploratory and confirmatory research, is robust to deviations for multivariate normal distributions, and is good for small sample sizes. Since the current study sample size is relatively small (241), Smart PLS was deemed to be more appropriate and befitting the purpose of the current study.

\section{Measurement Model}

A measurement model of the conceptual model with four latent variables was estimated. All constructs were modelled using reflective indicators. Construct reliability was assessed using composite reliability (CR) values and Cronbach's alpha (CA) values. As indicated in Table 2, the CR and the CA values were all above the recommended 0.6 in line with Hulland (1999). With values ranging from 0.759 to 0.839 for composite reliability, and from 0.616 to 0.793 for all Cronbach alphas, these indicators show that the scales are reliable. The internal consistency for constructs was assessed using the average variance extracted (AVE) measures following Fornell and Larker (1981) who suggested benchmarks of 0.5 in their studies. As reported in Table 2, all the AVE values reached the recommended benchmark; suggesting that all scale-items converged well on the constructs that they were measuring, and hence confirmed the existence of convergent validity.

Table 2. Descriptive statistics for accuracy analysis

\begin{tabular}{|c|c|c|c|c|c|c|c|c|c|}
\hline CONSTRUCTS & Mean & $\begin{array}{l}\text { Standard } \\
\text { Deviation }\end{array}$ & EfPA & EfCA & EfPC & EfRI & $\begin{array}{l}\text { Composite } \\
\text { Reliability }\end{array}$ & AVE & $\begin{array}{c}\text { Cronbach's } \\
\text { Alpha }\end{array}$ \\
\hline $\begin{array}{l}\text { Eco-friendly product } \\
\text { attributes } \\
\text { (EfPA) }\end{array}$ & 4.106 & 0.521 & 0,652 & & & & 0.759 & 0.425 & 0.793 \\
\hline $\begin{array}{l}\text { Customer-related } \\
\text { Attributes (characteristics) } \\
\text { (EfCA) }\end{array}$ & 3.798 & 0.573 & $0.397 *$ & 0.717 & & & 0.839 & 0.514 & 0.719 \\
\hline $\begin{array}{l}\text { Eco-friendly Product } \\
\text { Consumption decision } \\
\text { (EfPC) }\end{array}$ & 3.413 & 0.519 & 0.289 & $0.147^{*}$ & 0.689 & & 0.769 & 0.475 & 0.683 \\
\hline $\begin{array}{l}\text { Eco-friendly Repurchase } \\
\text { Intentions } \\
\text { (EfRI) }\end{array}$ & 3.211 & 0.503 & 0.371 & $0.193^{*}$ & 0.183 & 0.591 & 0.747 & 0.349 & 0.618 \\
\hline
\end{tabular}

Notes: Diagonal elements are square roots of AVE; off-diagonal elements are correlations. ${ }^{*}$ shows correlations are significant at $\mathrm{p}<0.05$ (twotailed); otherwise, correlations are significant at $\mathrm{p}<0.001$ (two-tailed), Eco-friendly product attributes (EfPA), Customer-related Attributes (characteristics)(EfCA), Eco-friendly Product Consumption decision (EfPC), Eco-friendly Repurchase Intentions (EfPI), C.R.: Composite Reliability; AVE: Average Variance Reliability

* Scores: 1 - Strongly Disagree; 3 - Neutral; 5 - Strongly Agree

To assess discriminant validity, the AVE of the construct should be greater than the shared variance between the construct and the other model constructs (Bertea, 2010). Table 2 also reports the correlations of the variables, as well as the square roots of AVE values on the diagonal. Results show that the diagonal figures are greater than the correlation figures in the corresponding rows and columns, confirming that discriminant validity indeed exist. 


\section{Structural Modeling Results}

The statistical significance of each path was estimated using a Smart PLS bootstrapping method utilising 241 resamples to obtain $t$-values (Chin \& Newsted, 1999). Smart PLS software does not provide goodness-of-fit measures for the full path model as like LISREL and AMOS, but it provides only $\mathrm{R}^{2}$ values for the dependent variables. However, a method to calculate a global goodness-of-fit (GoF) measure was proposed by Amato, Vinzi and Tenenhaus (2004), and this method takes into account both the quality of the measurement model and the structural model (Delafrouz et al. 2014).

The acceptable model is indicated by the chi-square value (CMin/DF) of 2.57 in line with the recommended threshold level of $<0.3$. The root mean square error of approximation (RMSEA) value of 0.063; and the GFI, CFI, RFI, IFI, TLI and NFI with the values of $0.913,0.921,0.903,0.952,0.947$ and 0.901 respectively, are within the recommended levels of greater than 0.900 (Wetzels et al. 2009). It could be concluded that the obtained data fits the model well as all the indicators revealed acceptable fit for the measurement model. Figure 2 illustrates these results.

Figure 2. Measurement and Structural Model Results

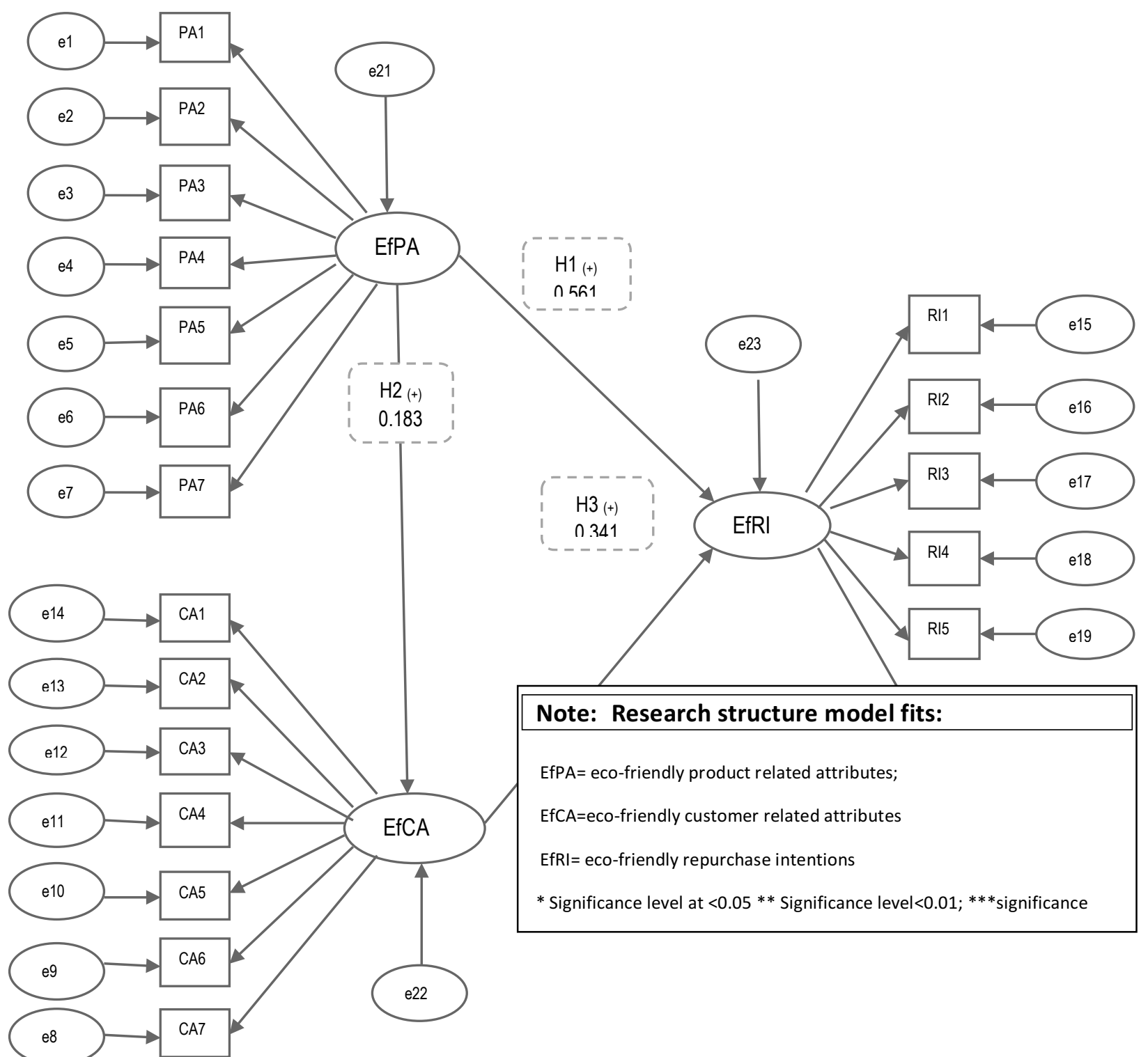

Copyright by author(s); $\underline{\mathrm{CC}-\mathrm{BY}}$ 
Table 3 presents the final results of the path analysis on the structural model, along with the path estimates and hypotheses tests. Support for the study hypotheses, labeled on their corresponding paths in Figure 2, could be ascertained by examining the directionality (positive or negative) of the path coefficients. The standardised path coefficients are expected to be at least 0.2, and preferably greater than 0.3 (Chin \& Newsted, 1999). These results reveal that the overall eco-friendly product attributes (EfPA) bears positive impacts on both eco-friendly repurchase intentions (EfRI) and eco-friendly customer-related attributes (EfCA) of retail customers, while eco-friendly customer-related attributes (EfCA) positively impacts eco-friendly repurchase intentions (EfRI).

Table 3. Results of hypotheses testing

\begin{tabular}{|c|c|c|c|c|c|}
\hline Hypotheses & Path & & & Estimate & Result \\
\hline $\begin{array}{l}\text { H1: Eco-friendly product related attributes } \\
\text { (EfPA) positively impacts shoppers' intentions to } \\
\text { repeat purchase eco-friendly retail products (EfRI) }\end{array}$ & EfRI & $<-$ & EfPA & $0.561 * * *$ & Supported \\
\hline $\begin{array}{l}\text { H2: Customers' } \\
\text { attributes/characteristics (EfCA) positively } \\
\text { influences their intentions to repeat purchase eco- } \\
\text { friendly retail products (EfRI) }\end{array}$ & EfRI & $<-$ & EfCA & $0.341 * *$ & Supported \\
\hline $\begin{array}{l}\text { H3: Eco-friendly product related attributes } \\
\text { (EfPA) have a positive relationship with eco- } \\
\text { friendly customers attributes (EfCA) }\end{array}$ & EfCA & $<-$ & EfPA & $0.183 * * *$ & Supported \\
\hline
\end{tabular}

Significant at $* \mathrm{P}<0.05 ; * * \mathrm{P}<0.01 ; * * * \mathrm{P}<.001 ; \mathrm{CMIN}=1022.37, \mathrm{df}=397.81 ; \chi 2 /(\mathrm{df})=2.57 ; \quad \mathrm{GFI}=0.913$; $\mathrm{IFI}=0.952 ; \mathrm{CFI}=0.921 ; \mathrm{RFI}=0.903 ; \mathrm{TLI}=947 ; \mathrm{NFI}=0.901 ; \mathrm{RMSEA}=0.063$

Table 3 reports the estimated model, illustrating the directional and magnitude of the impact of the standardized path coefficients. All the corresponding path coefficients of the hypotheses exhibited observable existence of positive relationships between online satisfaction, loyalty and repurchase intentions. Table 6 reports on these results. Results provided support for the entire proposed model; path coefficients for the three hypotheses (H1, H2 and H3) significant at a confidence level (p-value) of 0.001 . Where AVE represent the average of all AVE values for the research variables, while $\mathrm{R}^{2}$ represents the average of all $\mathrm{R}^{2}$ values in the full path model. The calculated global goodness-of-fit $(\mathrm{GoF})$ is 0.362 , which slightly exceeds the recommended threshold of GoF $>0.36$ suggested by Wetzels et al. (2009). Thus, this study concludes that the research model provides an overall goodness-of-fit.

\section{DISCUSSION OF RESULTS}

Previous studies (Laroche et al., 2002; Manaktola \& Jauhari, 2007), have demonstrated that retail customers' ecofriendly attitudes positively affect their resultant repurchase intentions. For this study, descriptive data suggest respondents' consciousness and openness to ongoing eco-friendly discourse. The purpose of this study was to investigate the influence of both eco-friendly product attributes and eco-friendly customer-related attributes on ecofriendly retail product repurchase intentions of South Africans. It was clear from survey results that South African customers are increasingly justifying eco-friendly product consumption aimed at protecting the environment. This is consistent with Olivia and Kallenberg (2003), who identified that customers are more willing to pay high prices for eco-friendly products and services. Results showed that respondents find it easy to evaluate their own eco-friendly intangible attributes in line with Creusen and Schoormans (2005). EfRI is relatively tangible and more visible when customers evaluate and make their purchase decisions (Monroe \& Krishnan, 1985). On the same note, EfPA, such as product design and quality, are relatively tangible and more visible to retail customers for evaluation. Respondents could evaluate EfPA subjectively based on their needs and perceptions. More precisely, our preliminary results suggest that EfCA may moderate the relationship between EfPA and EfRI. The results further show that customers are willing to pay a premium to support grocery retailers' growth and to sponsor product improvements as well as EfPA enhancements (Olivia \& Kallenberg, 2003). 
The results in Table 3 and Figure 2 provide support for all the three (3) hypotheses (H1, H2 and H3). The results in Table 3 and Figure 2 indicate that there is a significant positive relationship between eco-friendly product-related attributes and eco-friendly repurchase intentions. Therefore, H1 is supported, a positive impact of eco-friendly product attributes on eco-friendly repurchase intentions which is fairly similar to the results of some other researches including those of (Chen, 2010) and Boztepe (2012) who affirmed the said relationship. H2 is also supported as it posited a positive association between eco-friendly customer-related attributes and eco-friendly repurchase intentions. Although the standardised coefficient of eco-friendly product-related attributes and eco-friendly customer attributes is positive (0.183) and justifying the posited H3, it is surprisingly less significant than the other two. It could be concluded that eco-friendly customer-related attributes (EfCA) could have moderating effects on the relationship between eco-friendly product-related attributes (EfPA) and eco-friendly repurchase intentions (EfRI). Retailers should understand their customers and that the attributes of their products have impact on their customer retention strategies. There is a need to understand that once customers experience the favorable eco-friendly attributes of a product (e.g. organic foods, healthy natural air, etc.), they are likely to develop intentions to increase consumption of such products and hence enhanced EfRI.

\section{CONCLUSION}

It is generally accepted that retailers are judged on the basis of business ethics, social accountability, and socioeconomic awareness among other variables. This is because stakeholders are becoming eco-friendly, increasingly supporting issues of sustainability and environmental consciousness (Radwan et al. 2010). These trends are encouraging retailers to move towards eco-friendly behaviours. As the study revealed that eco-friendly attributes impact favorably on consumers' intentions to repurchase eco-friendly products, more efforts must be made to communicate eco-friendly practices and products to South African consumers and the public to assist product selection and induce active participation (Chen, 2010) in eco-friendly consumption.

From the reported results, this paper argues that successful eco-friendly orientated retailers would feasibly benefit from eco-friendly products/services if they effectively communicate eco-friendly product attributes (Creusen \& Schoormans, 2005) and foster eco-friendly customer-related attributes in their marketing efforts (Boztepe, 2012). The growing popularity of green consumption, which currently is largely due to media coverage of environmental concerns, must be included in their operational and communication strategies. Manaktola and Jauhari (2007) suggest that communication and channeling can help manipulate the public's perception and behaviour. It would therefore be argued that a retailer with sound and reputable eco-friendly practices could appeal to stakeholders, enhance employee morale, and consequently enjoy financial prosperity (Radwan et al. 2010).

For South African retailers, being environmentally friendly is the best way to encourage eco-friendly repurchase intentions and to spread word-of-mouth. Therefore, their operations should actively educate individuals through ecofriendly campaigns and informal education through the use of brochures, exhibitions, seminars, etc. Although some eco-friendly practices may be inconvenient and costly (e.g., recycling, reducing pollution or saving natural resources), such practices could persuade consumers to support those retailers committed to eco-friendly practices (Radwan et al. 2010). These efforts often induce positive perceptions towards eco-friendly behaviours, as well as enhance their perceived importance of being environmentally friendly (Chen, 2010). In other words, consumers are more likely to believe that eco-friendly retailers act responsibly towards the environment and their livelihoods; this results in increased eco-friendly repurchase intentions.

\section{Implications}

It can be said that consumers in South Africa have recently started to realize the importance of environmental issues and the subsequent health problems. They have gradually become more open to environmental protection issues and sensitive to eco-friendly product consumption. The findings of the study will be of importance to wholesalers and retailers who develop and market eco-friendly products and services. It will also be vital for the wholesale and retail sector in its effort to drive customers' purchase behaviour towards ecologically sensitive consumption (Lai \& Wong, 2012). This study projected some implications on the approaches to motivate eco-friendly product consumption and pricing, which will be useful for retailers and wholesalers to devise marketing plans to promote ecological consumption patterns, and thus facilitating the environmental sustainability. 


\section{Limitations}

While this study provided some insight on various significant issues, there are some limitations that reveal opportunities for future research enquiries. Firstly, most respondents were younger age consumers from a region in South Africa, one of the limitations of this study. Young South African consumers, aged between 15 and 30, behave differently in many ways from children or adults in other age groups, and from other parts of the world. Future studies could use other segments of the retail market. Secondly, the current study did not classify customer groups by the types of retailers (e.g., economy, mid-scale, upscale, or luxury) when examining eco-friendly attributes, demographics, and eco-friendly repurchase intentions. Future studies should investigate if the differences in ecofriendly behaviours exist among different age-groups of customers in various segments of the retailers.

\section{AUTHOR INFORMATION}

Job Dubihlela is an Associate Professor at the cape Peninsula University of Technology. He is currently involved in a research programs on the social enterprises audits, environmental and sustainability issues in South Africa. He holds a Ph.D from the North West University.

Tandiswa Ngxukumeshe is a senior lecturer who recently completed her PhD at the Nelson Mandela Metropolitan University. She has vast experience in retail business management issues.

\section{REFERENCES}

Ahn, S., \& Park, S. (1998). A study of consumer's environmental consciousness and purchasing behavior of environmental goods. Journal of Resource Development, 18(1), 14-25.

Balderjahn, I. (1988). Personality variables and environmental attitudes as predictors of ecologically responsible consumption patterns. Journal of Business Research, 17(1), 51-56.

Bang, H., Ellinger, A., Hadjimarcou, J., \& Traichal, P. (2000). Consumer concern, knowledge, belief, and attitude toward renewable energy: An application of the reasoned action theory. Psychology Marketing, 17(6), 449-468.

Chen, C. (2001). Design for the Environment: A quality-based model for green product development. Management Science, $47(2), 250-263$.

D'Souza, C., Taghian, M., \& Khosla, R. (2007). Examination of environmental beliefs and its impact on the influence of price, quality and demographic characteristics with respect to green purchase intention. Journal of Targeting, Measurement and Analysis for Marketing, 15(2), 69-78.

Fishbein, M. (1967). An investigation of relationship between beliefs about an object and the attitude toward the object. Human Relations, 16, 233-240.

Kalafatis, S., Pollard, M., East, R., \& Tsogas, M. (1999). Green marketing and Ajzen;s theory of planned behavior: A crossmarket examination. Journal of COnsumer Marketing, 16(5), 441-460.

Kollmus, A., \& Agyeman, J. (2002). Mind the gap: why do people act environmentally and what are the barriers to proenvironmental behaviour? Environmental Education Research, 8, 239-260.

Laroche, M., Bergeron, J., \& Barbaro-Forleo, G. (2001). Targeting consumers who are willing to pay more for environmentally friendly products. Journal of Consumer Marketing, 18(6), 503-520.

Laroche, M., Bergeron, J., Tomiul, M., \& Barbaro-Forleo, G. (2002). Cultural differences in environmental knowledge, attitudes and behaviours of Canadian consumers. Canadian Journal of Administrative Sciences, 19(3), 267-283.

Manaktola, K., \& Jauhari, V. (2007). Exploring consumer attitude and behaviour towards green practices in the lodging industry in India. Internal Journal of Contemporary Hospitality Management, 19(5), 364-377.

Morris, L., Hastak, M., \& Mazis, M. (1995). Consumer comprehension of environmental advertising and labelling claims. The Journal of Consumer Affairs, 29(2), 325-351.

Park, H., \& Oh, S. (2005). THe influence of materialism and environment consciousness on recycling attitude and behavior of clothing. Journal of the Korean Home Economics Association, 43(10), 167-177.

Park, K. (2000). A theoretical study on the behaviours of the environmentally concerned consumers. Kyongju University Research, 43(10), 295-309.

Sung, Y. (2005). A study on the environmental consciousness and behaviou of the consumers in Incheon Area. Korean Home Management Association, 23(3), 35-51.

Tan, B., \& Yeap, P. (2012). What drives green restaurant patronage intention? International Journal of Business and Management, 7(2), 215-223.

Vining, J., \& Ebreo, A. (1990). What makes a recycler? A comparison of recyclers and nonrecyclers. Environmental Behavior, 22(1), 55-73.

Wagner, S. (1997). Understanding green consumer behaviour: A qualitative cognitive approach. London, UK: Routledge. 
Wan, P. (2007). The use of environmental management as a facilities management tool in the Macao Hotel sector. Facilities, 25(7/8), 286-295.

Wasik, J. (1996). Green marketing and management: A global perspective. United Kingdom: Blackwell Publishers Ltd.

Widegren, O. (1998). The new environmental paradigm and personal norms. Journal of Environment and Behavior, 30(1), 75100.

Wiener, J., \& Sukhdial, A. (1990). Recycling of solid waste: directions for future research. AMA Summer Educators' Conference Proceedings. 1, pp. 389-392. Chicago, IL: American Marketing Association. 


\section{NOTES}

